\title{
Clinic-Pathological Aspects of Spleen Hemophagocytic Histiocytic Sarcoma in a Dog
}

\author{
Thaynan Cunha Vieira, Luiz Flávio Telles, Karen Yumi Ribeiro Nakagaki \& Geovanni Dantas Cassali
}

\begin{abstract}
Background: Histiocytes are cells that differentiate into macrophages and dendritic cell lines from bone marrow CD34+ stem cells. The hemophagocytic histiocytic sarcoma (HHS) is the only malignant neoplasm originating from macrophage lineages, being a variation of histiocytic sarcoma (HS), originated from dendritic cells. In general, the HHS shows aggressive biological behavior, due to the erythrophagocytosis characteristic of this disease and overall average survival around seven weeks, affecting mainly Bernese Mountain Dog, Rottweiler and Golden Retriever breeds. Therefore, the objective of this work is to report the case of a dog with HHS, emphasizing the clinical aspects and its diagnostic method.

Case: An 8-year-old bitch Rottweiler, was attended with history of inappetence and prostration. The complete blood count showed normochromic normocytic anemia, monocytosis and thrombocytopenia, with serum urea levels below the reference value for the specie in the biochemical examination. The abdominal ultrasound highlighted splenomegaly, with heterogeneous parenchyma and presence of a vascularized mass and an enlarged splenic vein. Thoracic radiographic examination showed multifocal and rounded radiopaque structures in the pulmonary parenchyma, suggesting metastatic formation. Rapid serological tests for detection of the main hemoparasitosis antibodies were negative, as well as negative Coombs test. The animal was submitted to exploratory laparotomy with medial line access and posterior splenectomy. The spleen microscopic evaluation revealed neoplastic proliferation cells in mantle arrangement and solid nests areas, supported by a fine fibrovascular stroma. The cells had broad and eosinophilic cytoplasm, round nuclei and some pleomorphism, rude chromatin and evident nucleoli. It was also observed the presence of marked anisocytosis and anisocariosis, hemophagocytic activity, and 27 mitoses in 10 fields $(40 \mathrm{x}$ ). There were atypical mitoses and necrosis and extensive hemorrhaged areas. These histopathological findings suggested a histiocytic malignant neoplasia and immunohistochemical analysis was performed to define a better histiocytic neoplasm origin. The neoplastic cells showed positive imunostaining for CD11d and Iba1 and negative imunostaining for CD3 and CD20, as well as a proliferative index of 80\%, supporting the diagnosis of HHS in the animal's spleen. The following hematological analyzes demonstrated persistence of anemia, worsening of thrombocytopenia, prolongation of activated partial thromboplastin time, hypoproteinemia with hypoalbuminemia, serum increase of creatinine, alkaline phosphatase and total bilirubin. Myelogram showed erythrocyte and granulocytic lineage hypoplasia, thrombocytic aplasia and more than $50 \%$ of macrophages in bone marrow cell population. The animal's clinical condition worsened rapidly, after successive transfusions and administration of chemotherapy with lomustine, leading to death 14 days after the surgery.

Discussion: HHS is the most serious clinical presentation among histiocytic disorders, conferring an extremely unfavorable prognosis. In addition, the scientific literature that specifically addresses the HHS is rare, with therapeutic extrapolations being performed for the treatment of HS from dendritic cells. The racial predisposition and clinical findings, associated with hematological changes, histopathological analysis and confirmation by immunohistochemistry allowed the diagnosis of HHS, a rare and underreported neoplasm, with aggressive biological behavior and with still inefficient treatment in veterinary medicine.
\end{abstract}

Keywords: immunohistochemistry, Rottweiler, macrophages, erythrophagocytosis. 
T.C. Vieira, L.F. Telles, K.Y.R. Nakagaki \& G.D. Cassali. 2021. Clinic-Pathological Aspects of Spleen Hemophagocytic Histiocytic

\section{INTRODUCTION}

Histiocytes are cells that differentiate into macrophages and dendritic cell lines from bone marrow CD34+ stem cells, and neoplastic proliferation of both cells may occur $[4,8,10]$. The pathologies that affect these cells are called histiocytic disorders and can be classified into histiocytoses, histiocytomas, histiocytic sarcomas (HS) and hemophagocytic histiocytic sarcomas (HHS) [6,10]. Among these pathologies, HHS is the only one from macrophage lineages, being a variation of $\mathrm{SH}$, from dendritic cells $[3,13]$. In general, HHS exhibits an aggressive biological behavior, due to the erythrophagocytosis characteristic of this disease $[4,10]$. Dogs can be considered an experimental model for hemophagocytic syndrome in humans, affecting mainly Bernesse Mountain Dog, Rottweiler and Golden Retriever [2,5,11,14]. Furthermore, in HHS there is no sexual predisposition, being described in dogs aged 2.5 to 13 years [3]. Its etiology is related to mutations in tumor suppressor genes, initially affecting the spleen and bone marrow, progressing to the lungs and liver, with uncommon lymph nodes involvement $[2,5,11,14]$.

The overall average survival is quite short, around seven weeks, leading the animal to death due to complications of erythrophagocytosis by neoplastic cells and coagulopathies $[3,6,10]$. Therefore, the objective of this work is to report the clinical case of a dog with HHS, emphasizing the clinical aspects of the disease and its diagnostic method.

\section{CASE}

An 8-year-old bitch Rottweiler, was attended with history of inappetence and prostration. The complete blood count showed normochromic normocytic anemia (hematocrit $30.6 \%$; reference interval [RI]: 37.3

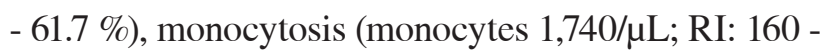
$1,120 / \mu \mathrm{L}$ ) and thrombocytopenia (platelets $82,000 / \mu \mathrm{L}$; RI: 148,000 - 484,000/ $\mu \mathrm{L}$ ), with serum urea levels below the reference value for the specie in the biochemical examination (blood urea nitrogen $6 \mathrm{mg} / \mathrm{dL}$; RI: 7 - 27 $\mathrm{mg} / \mathrm{dL}$ ). The abdominal ultrasound highlighted splenomegaly, with heterogeneous parenchyma and presence of a vascularized mass and an enlarged splenic vein. Besides that, thoracic radiographic examination showed multifocal and rounded radiopaque structures in the pulmonary parenchyma, suggesting metastatic formation. Rapid serological tests ${ }^{1}$ for detection of Erlichia ewingii, Erlichia canis, Anaplasma phagocytophilum, Anaplasma platys, Borrelia burgdorferi, Dirofilaria immitis and Leishmania infantum antibodies were negative, as well as negative coombs test ${ }^{2}$. Therefore, the animal was submitted to exploratory laparotomy with medial line access and posterior splenectomy.

The macroscopic spleen examination showed an increase in size with bulging edges and multiple nodules distributed diffusely on its surface. When cut, multiple nodules of solid surface, heterogeneous aspect with brown coloration and reddish areas, with precise limits, were observed. The organ was fixed in $10 \%$ buffered formalin, processed by routine histopathological technique. For microscopic evaluation, the tissue was

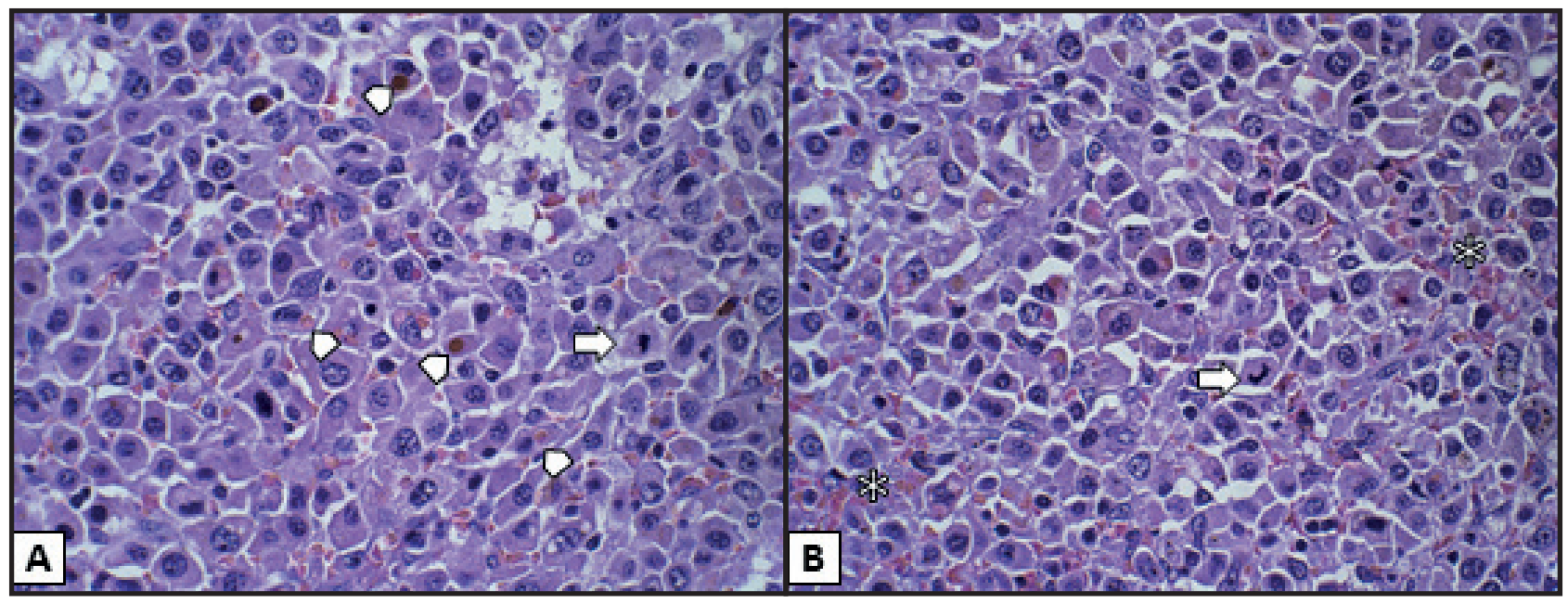

Figure 1. Histiocytic sarcoma in a dog's spleen. A \& B- Neoplastic cells proliferation in mantle arrangement and solid nests areas, with round nuclei, pleomorphism, rude chromatin, evident nucleoli and mitosis (arrows) [H\&E; 600x]. A- Hemophagocytic activity showing erythrocytes and hemosiderin in the cytoplasm (arrows head). B- Hemorrhaged areas (asterisks). 


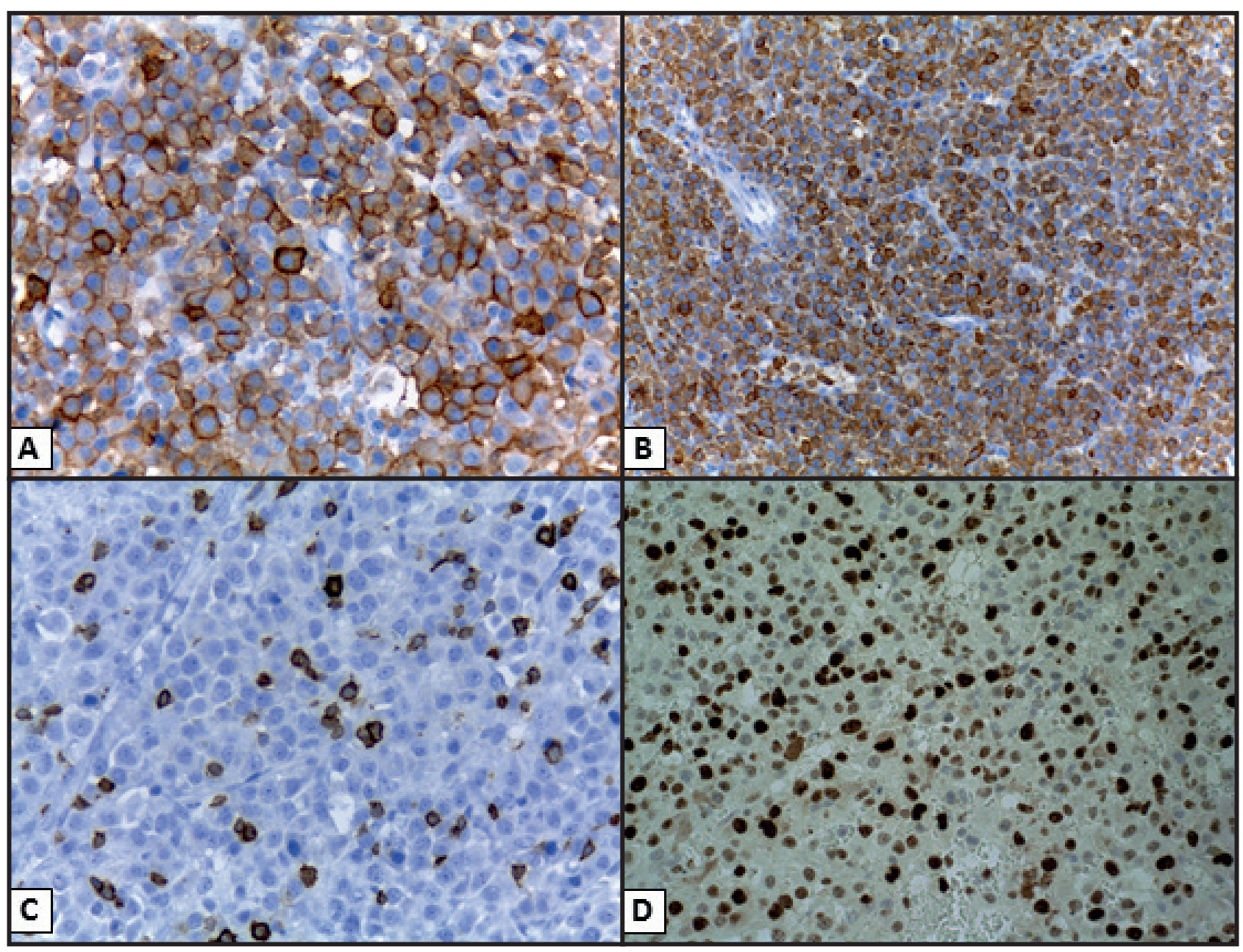

Figure 2. Immunohistochemistry for hemophagocytic histiocytic sarcoma diagnostic in a dog's spleen. A- Positive immunostaining for CD11d. B- Positive immunostaining for Iba1. C- Negative immunostaining in neoplastic cells for CD3. D- Proliferative index of 80\% (Ki67).

stained by hematoxylin ${ }^{3}$ and $\operatorname{eosin}^{4}(\mathrm{H} \& \mathrm{E})$, revealing neoplastic cells proliferation in mantle arrangement and solid nests areas, supported by a fine fibrovascular stroma. The cells had broad and eosinophilic cytoplasm, round nuclei and some pleomorphism, rude chromatin and evident nucleoli. It was also observed the presence of marked anisocytosis and anisocariosis, hemophagocytic activity, and 27 mitosis in 10 fields $(40 \mathrm{x})$. There were atypical mitoses and necrosis and extensive hemorrhaged areas (Figure 1). The histopathological findings suggested a histiocytic malignant neoplasia and immunohistochemical analysis was performed to define a better histiocytic neoplasm origin.

The immunohistochemistry evaluated the $\mathrm{CD} 11 \mathrm{~d}^{5}, \mathrm{Iba}^{6}{ }^{6}, \mathrm{CD}^{7}, \mathrm{CD} 20^{8}$ and Ki-67 $7^{7}$ immunoexpression. The neoplastic cells showed positive immunostaining for CD11d and Iba1 and negative immunostaining for CD3 and CD20, as well as a proliferative index of $80 \%$, supporting the diagnosis of HHS in the animal's spleen (Figure 2).
After the surgical procedure, it was observed the persistence of normochromic normocytic anemia, worsening of thrombocytopenia (platelets $2,000 / \mu \mathrm{L}$ ), prolongation of activated partial thromboplastin time (aPTT) (183 s; RI: 72 - $102 \mathrm{~s}$ ), hypoproteinemia (total protein $3.7 \mathrm{~g} / \mathrm{dL}$; RI: 5.2 - $8.2 \mathrm{~g} / \mathrm{dL}$ ) with hypoalbuminemia (albumin $1.6 \mathrm{~g} / \mathrm{dL}$; RI: $2.3-4.0 \mathrm{~g} / \mathrm{dL}$ ), serum increase of creatinine (1.9 mg/dL; RI: $0.5-1.8 \mathrm{mg} / \mathrm{dL}$ ), alkaline phosphatase (278 U/L; RI: 23 - $212 \mathrm{U} / \mathrm{L}$ ) and total bilirubin $(2.8 \mathrm{mg} / \mathrm{dL} ; \mathrm{RI}:<0.9 \mathrm{mg} / \mathrm{dL})$, in addition to mild nephropathy and hepatomegaly in abdominal ultrasound. Myelogram showed erythrocyte and granulocytic lineage hypoplasia, thrombocytic aplasia and more than $50 \%$ of macrophages in bone marrow cell population. The animal's clinical condition worsened rapidly, after successive transfusions and administration of chemotherapy with lomustine ${ }^{9}$ (Citostal - $90 \mathrm{mg} / \mathrm{m}^{2}$ ), leading to death 14 days after surgery. 


\section{DISCUSSION}

HHS is the most serious clinical presentation among histiocytic disorders, conferring an extremely unfavorable prognosis [10]. Due to aggressive biological behavior and nonspecific clinical manifestation, early diagnosis is very rare to be performed, resulting in a low survival time for patient [8]. In addition, the scientific literature that specifically addresses the HHS is rare, with therapeutic extrapolations being performed for the treatment of HS from dendritic cells [10]. Such statements could be seen in the present report with a 14-day survival.

The hematological alterations, initially unspecific, were elucidated after the definitive diagnosis of HHS, obtained through the immunophenotyping of the affected organ. The anemia observed in the patient can be explained due to the activity of mutated macrophages that performed erythrophagocytosis. This anomalous cellular behavior is consistent with the literature that describes not only red blood cells, but also hemosiderin in the cytoplasm of macrophages, although leukocyte and platelet phagocytosis is not so common $[11,15]$. Monocytosis, also observed in this case, can also be explained because monocytes are cells that differentiate into macrophages after migration to tissues [16,17]. In addition, spleen and bone marrow are organs in which this type of phagocytic activity of neoplastic cells is usually observed, manifesting clinically through diffuse splenomegaly with ill-defined masses $[3,4,10]$. The myelogram, in its turn, showed the presence of macrophages representing more than $50 \%$ of the cell population, thus being an important feature in the differentiation of hemophagocytic syndromes [18].

Biochemical and hemostatic alterations in the serum evaluation are also cited in the literature, highlighting hypoalbuminemia, hypercholesterolemia, hypoproteinemia, increased aPTT and discrete hyperbilirubinemia due to the neoplastic inflammatory process, all observed in the report with exception hypercholesterolemia, without interference in the final diagnosis $[6,10]$. Increased creatinine and decreased urea, as well as increased serum alkaline phosphatase are associated with disease progression in this case $[1,7]$. The observed thrombocytopenia is in line with the literature, which points a decrease in the absolute number of platelets due to their consumption, exacerbating the coagulation disorder [10]. It is essential that in the diagnosis of HHS, other anemia possibilities are discarded, such as hemoparasitosis and immunemediated hemolytic diseases $[8,10]$. Therefore, infections by Erlichia ewingii, Erlichia canis, Anaplasma phagocytophilum, Anaplasma platys, Borrelia burgdorferi, Dirofilaria immitis and Leishmania infantum were discarded through immunochromatography, as well as immune-mediated hemolytic anemia by the negative coombs test.

In the histopathological analysis of the spleen, high atypia and intense hemophagocytic activity of neoplastic cells were observed, justifying the initial hematological findings $[10,11,15]$. Although the histopathological findings suggest the diagnosis of HS of macrophage origin, the confirmatory diagnostic can only be performed through the immunophenotypic characterization by the immunohistochemistry technique $[4,8,15]$.

The HHS macrophages in the spleen and bone marrow express an antigenic profile on the membrane that allow differentiates them from dendritic cells in the HS [8-10]. These macrophages express CD11d, a beta- 2 integrin responsible for the molecules adhesion, whereas dendritic cells express predominantly CD11c [10]. In addition, the identification of histiocytic proliferation in general can be evidenced by the expression of the ionizing calcium-binding protein 1 (Iba1) [9]. Thus, the positive immunostaining for Ibal and CD11d in the neoplastic cells in this report supported the diagnosis of HHS.

On the other hand, hepatosplenic T-cell lymphoma is also characterized by anemia and thrombocytopenia, like hemophagocytic syndrome, and can be a differential in the diagnosis of HHS, having positive immunostaining for CD3 [9]. The fact that lymphomas in general also express $\beta$ - 2 integrins makes it important to differentiate a possible lymphoid origin of these tumors, observing the immunoexpression of CD3, CD79a and CD20, for example in these cases [8]. Considering these informations, the negative immunostaining of the neoplastic cells in this study for CD3 and CD20 could confirm the final diagnosis of HHS in the spleen.

The treatment performed on this patient, however, was merely palliative, since the rapid evolution did not allow the realization of more complex chemotherapy protocol. The splenectomy associated with adjuvant chemotherapy with lomustine and successive blood transfusions were not sufficient to contain 
neoplastic progression. Lomustine is a highly lipophilic nitrosurea class of antineoplastic, featuring high penetrability of this drug in tissues, being the first choice for the treatment of histiocytic sarcomas [12]. Due to the advanced stage of the disease, with radiological signs suggestive of pulmonary metastasis, the patient died before it was possible to perform the second dose of chemotherapy with the maximum tolerated dose.

The racial predisposition and clinical findings, associated with hematological changes, histopathological analysis and confirmation by immunohistochemistry allowed the diagnosis of HHS, a rare and underreported neoplasm, with aggressive biological behavior and with still inefficient treatment in veterinary medicine.

\section{MANUFACTURERS}

${ }^{1}$ Idexx Laboratories. Westbrooke, ME, USA.

${ }^{2}$ Alvedia - Alice Veterinary Diagnostic. Limonest, France.

${ }^{3}$ Neon Comercial Ltda. Suzano, SP, Brazil.

${ }^{4}$ Labsynth Produtos para Laboratórios. Diadema, SP, Brazil.

${ }^{5}$ University of California (Dr. Peter Moore). Davis, CA, USA.

${ }^{6}$ Fujifilm Wako Chemicals U.S.A. Corporation. Richmond, VA, USA.

${ }^{7}$ Dako North America Inc. Carpinteria, CA, USA.

${ }^{8}$ Thermo Fischer Scientific Inc. Waltham, MA, USA.

${ }^{9}$ Bristol-Myers Squibb Company. New York, NY, USA.

Acknowledgements. We would like to thank Dr. Rafael of VetMol Laboratory for the collaboration in immunohistochemical analysis.

Declaration of interest. The authors report no conflicts of interest. The authors alone are responsible for the content and writing of the paper.

\section{REFERENCES}

1 Allison R.W. 2012. Laboratory Evaluation of the Liver. In: Thrall M.A., Weiser G., Allison R.W. \& Campbell T.W. (Eds). Veterinary Hemathology and Clinical Chemistry. 2nd edn. Danvers: Wiley-Blackwell, pp.401-423.

2 Asada H., Ichii O., Tomiyasu H., Uchida K., Chambers J.K., Goto-Koshino Y., Ohno K., Kon Y. \& Tsujimoto H. 2019. The intratumor heterogeneity of TP53 gene mutations in canine histiocytic sarcoma. Journal of Veterinary Medical Science. 81(3): 353-356.

3 Cherpinski V.A., Gonçalves A.D., Viriatto F. \& Fam A.L.D. 2017. Sarcoma Histiocítico Hemofagocítico em um cão - Relato de Caso. Biociências, Biotecnologia e Saúde. 19: 148-150.

4 Clifford C.A., Skorupski K.A. \& Moore P.F. 2020. Histiocytic Diseases. In: Vail D.M., Thamm D.H. \& Liptak J.M. (Eds). Small Animal Clinical Oncology. 6th edn. St. Louis: Elsevier Inc., pp.791-810.

5 Hedan B., Thomas R., Motsinger-Reif A., Abadie J., Andre C., Cullen J. \& Breen M. 2011. Molecular cytogenetic characterization of canine histiocytic sarcoma: A spontaneous model for human histiocytic cancer identifies deletion of tumor suppressor genes and highlights influence of genetic background on tumor behavior. BMC Cancer. 11: 201. DOI: $10.1186 / 1471-2407-11-201$

6 Jark P.C. \& Rodigheri S.M. 2016. Distúrbios Histiocíticos. In: Daleck C.R. \& De Nardi A.B. (Eds). Oncologia em Cães e Gatos. 2.ed. Rio de Janeiro: Editora Roca, pp.661-671.

7 Meuten D. 2012. Laboratory Evaluation and Interpretation of the Urinary System. In: Thrall M.A., Weiser G., Allison R.W. \& Campbell T.W. (Eds). Veterinary Hemathology and Clinical Chemistry. 2nd edn. Danvers: Wiley-Blackwell, pp.322-377.

8 Moore P.F. 2014. A Review of Histiocytic Diseases of Dogs and Cats. Veterinary Pathology. 51(1): 167-184.

9 Moore P.F. 2017. Canine and Feline Histiocytic Diseases. In: Meuten D.J. (Ed). Tumors in Domestic Animals. 5th edn. Ames: John Wiley \& Sons Inc., pp.222-336.

10 Moore P.F., Affolter V.K. \& Vernau W. 2006. Canine hemophagocytic histiocytic sarcoma: A proliferative disorder of CD11d+ macrophages. Veterinary Pathology. 43(5): 632-645.

11 Mullin C. \& Clifford C.A. 2019. Histiocytic Sarcoma and Hemangiosarcoma Update. Veterinary Clinics of North America - Small Animal Practice. 49: 855-879.

12 De Nardi A.B., Reis Filho N.P. \& Viéra R.B. 2016. Quimioterapia Antineoplásica. In: Daleck C.R. \& De Nardi A.B. (Eds). Oncologia em Cães e Gatos. 2.ed. Rio de Janeiro: Roca, pp.333-378.

13 Picarsic J. \& Ronald J. 2018. Pathology of histiocytic disorders and neoplasms and related disorders. In: Abla O. \& Janke G. (Eds). Histiocytic Disorders. Cham: Springer International Publishing, pp.3-50.

14 Takada M., Smyth L.A., Thaiwong T., Richter M., Corner S.M., Schall P.Z., Kiupel M. \& Yuzbasiyan-Gurkan V. 2019. Activating Mutations in PTPN11 and KRAS in Canine Histiocytic Sarcomas. Genes. 10(7): 505. DOI: 10.3390/ genes 10070505 
T.C. Vieira, L.F. Telles, K.Y.R. Nakagaki \& G.D. Cassali. 2021. Clinic-Pathological Aspects of Spleen Hemophagocytic Histiocytic Sarcoma in a Dog.

15 Valli V.E.O., Bienzle D. \& Kiupel M. 2007. Hematopoietic System. In: Maxie M.G. (Ed). Pathology of Domestic Animals. 5th edn. v.3. Philadelphia: Elsevier, pp.107-324.

16 Weiser G. 2012. Introdution to Leukocytes and the Leukogram. In: Thrall M.A., Weiser G., Allison R.W. \& Campbell T.W. (Eds). Veterinary Hemathology and Clinical Chemistry. 2nd edn. Danvers: Wiley-Blackwell, pp.118-122.

17 Weiser G. 2012. Interpretation of Leukocyte Responses in Disease. In: Thrall M.A., Weiser G., Allison R.W. \& Campbell T.W. (Eds). Veterinary Hemathology and Clinical Chemistry. 2nd edn. Danvers: Wiley-Blackwell, pp.127-139.

18 Weiss D.J. 2002. Flow cytometric evaluation of hemophagocytic disorders in canine. Veterinary Clinical Pathology. 31(1): $36-41$. 